Article

\title{
Pigments in Extra-Virgin Olive Oils Produced in Tuscany (Italy) in Different Years
}

\author{
Cristina Lazzerini and Valentina Domenici * \\ Dipartimento di Chimica e Chimica Industriale, Università di Pisa, 56124 Pisa, Italy; lazzerinicristina@gmail.com \\ * Correspondence: valentina.domenici@unipi.it; Tel.: +39-050-2219-215
}

Academic Editor: Andrea Buettner

Received: 8 March 2017; Accepted: 25 March 2017; Published: 29 March 2017

\begin{abstract}
Pigments are responsible for the color of olive oils, and are an important ingredient that is directly related to the quality of this food. However, the concentration of pigments can vary significantly depending on the climate conditions, harvesting time, and olive cultivars. In this work, we quantified the main pigments in several extra-virgin olive oils produced from a blend of three cultivars (Moraiolo, Frantoio, and Leccino) typical of Tuscany (Italy) harvested in three different years: 2012, 2013, and 2014. Pigments-namely, $\beta$-carotene, lutein, pheophytin A, and pheophytin B-were quantified by a method based on the mathematical analysis of the near ultraviolet-visible absorption spectra of the oils. Data were analyzed by a multivariate statistical approach. The results show that the pigments' content of extra-virgin olive oils produced in 2014 can be well distinguished with respect to previous years. This can be explained by the anomalous climate conditions, which strongly affected Italy and, in particular, Tuscany, where the olives were harvested. This study represents an interesting example of how pigment content can be significant in characterizing olive oils. Moreover, this is the first report of pigment quantification in extra-virgin olive oils produced in Tuscany.
\end{abstract}

Keywords: olive oils; carotenoid; chlorophyll; ultraviolet-visible spectroscopy; multivariate analysis; $\beta$-carotene; lutein; pheophytin A; Tuscany

\section{Introduction}

Extra-virgin olive oil is an essential food in Mediterranean cuisine, and is nowadays an appreciated and recognized ingredient in many other cultures. Olive oil is produced from the olive fruits of the Olea europeae L. trees, and due to the high content of monounsaturated fatty acids and bioactive compounds [1], olive oil is considered beneficial for human health [2]. Among various types of olive oils, virgin olive oils (VOOs) and extra-virgin olive oils (EVOOs) are those with the highest content of minor compounds having bioactive properties (about $1 \%-2 \%$ ). They are divided into polar phenols and their derivatives, and non-polar (unsaponifiable) compounds, such as squalene and other triterpenes, sterols, tocopherols, and pigments [1,2]. Pigments in olive oils can be divided in two main classes: carotenoids and chlorophyll derivatives [3-5]; they are responsible for the color of olive oils [6], which is an important feature for the quality of EVOO. Moreover, pigments' bioactivity is associated with their healthy properties for several human organs, such as the brain and nervous system $[7,8]$.

Olive oils contain a relatively rich variety of carotenoids (i.e., $\beta$-carotene, lutein, violaxanthin, neoxanthin, and other xanthophylls) and chlorophyll derivatives (i.e., chlorophylls $\mathrm{A}$ and $\mathrm{B}$, pheophytins $\mathrm{A}$ and $\mathrm{B}$, and other minor derivatives) [3]. Their relative composition in olive oil derives from the initial pigment composition of the olive fruits and from all chemical transformations, such as those which are enzymatically driven, occurring at different stages of olive oil production [4]. The main factors affecting the pigment profile of olive fruits are the variety (or cultivar) [3,9-12], the ripening degree [13-15], the climate [16,17], and growing [18] conditions. Further influence on the 
final content and percentage of pigments in olive oil is from the specific conditions of oil production, such as malaxation stage and oil extraction [19-21].

Most papers reporting on pigment content in olive oils provide only the total amount of carotenoids and chlorophyll derivatives, determined by measuring the absorbance of olive oil dissolved in cyclohexane [6], or of olive oil directly as it is [22]. On the contrary, the identification and quantification of single pigments is usually done by the use of chromatographic methods, such as high performance liquid chromatographic (HPLC) with ultraviolet-visible (UV-vis) detection [23]. Recently, a new method based on the quantitative analysis of the absorption spectrum of olive oil in the near UV-vis range has been developed [24], able to determine the concentration of four main pigments: $\beta$-carotene and lutein among the carotenoids, and pheophytin $\mathrm{A}$ and pheophytin $\mathrm{B}$ among chlorophyll derivatives. This method has been applied to extra-virgin olive oil samples produced in several Mediterranean countries from different cultivars [5,14,25-27], confirming its validity, goodness, and high reproducibility in the quantification of the four main pigments present in olive oil.

In this work, we focus on the pigment content of extra virgin olive oil samples produced in Tuscany (Italy) in different harvesting years. The region of Tuscany (on the western coast of central Italy) is among Italy's leading olive oil producers, and EVOOs produced in this region-which represent about the $2 \%-4 \%$ of total Italian EVOO production [28,29]—are considered to be of very high quality. The main olive cultivars typical of Tuscany are Frantoio, Moraiolo, and Leccino [29]—each of them with characteristic properties. Frantoio is characterized by large fruits, Frantoio trees have high and constant productivity, good adaptation capacity, and weather-resistance; the organoleptic properties of olive oil produced by Frantoio are considered excellent. Moraiolo has a medium-low productivity, but high yields; it has a low resistance against different plant diseases, but it is resistant to windy and hot weather [29]. Leccino is very resistant to different weather conditions (cold, wind, temperature gaps, etc.), but has low resistance to fruit drop [28,29]. Leccino is sterile and needs to be pollinated, typically from Frantoio plants. In Tuscany, for both traditional and botanical reasons, monocultivar olive oil production is rare, while most high-quality Tuscan EVOOs (such as identificazione geografica protetta, IGP, and denominazione di origine protetta, DOP, labeled EVOOs) are obtained from a blend of these three varieties. The scientific interest in these cultivars is demonstrated by numerous studies, mainly dealing with the phenolic profiles and antioxidant properties [17,30,31], as well as sensorial and organoleptic features [32-34] of Tuscan EVOOs. Several works have investigated the effect of the ripening period and climate conditions [31,35], olive processing and extraction methods [36], and the effect of different storage conditions [34] on extra-virgin and virgin olive oils produced by these three Tuscan cultivars. So far, no works have been reported concerning the pigment content in extra virgin olive oils produced in Tuscany from the main cultivars Frantoio, Moraiolo, and Leccino.

In the present work, the pigment profile of a selection of EVOOs produced from a blend of these three varieties in several Tuscan growing areas and obtained in three different years (i.e., 2012, 2013, and 2014) was determined by analyzing their near ultraviolet-visible absorption spectra. Results are analyzed by a multivariate approach based on principal component analysis (PCA) and discussed taking into account the peculiarity of the 2014 crop season, which was characterized by one of the strongest olive fruit fly attacks in Tuscany [37].

\section{Materials and Methods}

\subsection{Samples}

Several EVOO samples produced in Tuscany (Italy) from Frantoio, Moraiolo, and Leccino varieties were provided by private producer companies. These samples were obtained from olives (fruits of Olea europaea, L. trees) harvested in three different seasons (2012, 2013, and 2014). In the case of 2012 samples, harvesting was performed from the 23rd of October to the 9th of November; 2013 samples were harvested from the 18th of October until the 11th of November; in the case of 2014 samples, harvesting was limited to the period from the 16th to the 28th of October. For all harvesting periods, 
the climate conditions are known and they can be found on the web $[38,39]$. The local areas of olive trees growing and olive harvesting are reported in Figure 1. Most of the samples were produced in areas close to the seaside (districts of Lucca, Livorno, Pisa, and Grosseto), and only few samples were produced in more inland areas (districts of Pistoia and Siena). These samples were labelled from T1 to T37. In particular, we had nine samples from the 2012 harvest (from T1 to T9), eighteen samples from the 2013 harvest (from T10 to T27), and ten samples from the 2014 harvest (from T28 to T37). The ripeness stage of olives at harvesting was purple (P)/black (B), according to the ripeness index defined by Loudiyi et al. [40]. All samples were classified as "extra virgin olive oils" by sensory characteristics (International Regulations, Reg. CE 640/2008) and analytical indices (European Regulation, Reg. CE 1234/2007, annex XVI). All EVOO samples were stored in dark glass bottles in the dark at $5{ }^{\circ} \mathrm{C}$, and the chemical-physical analysis was performed three months after olive oil production [41].

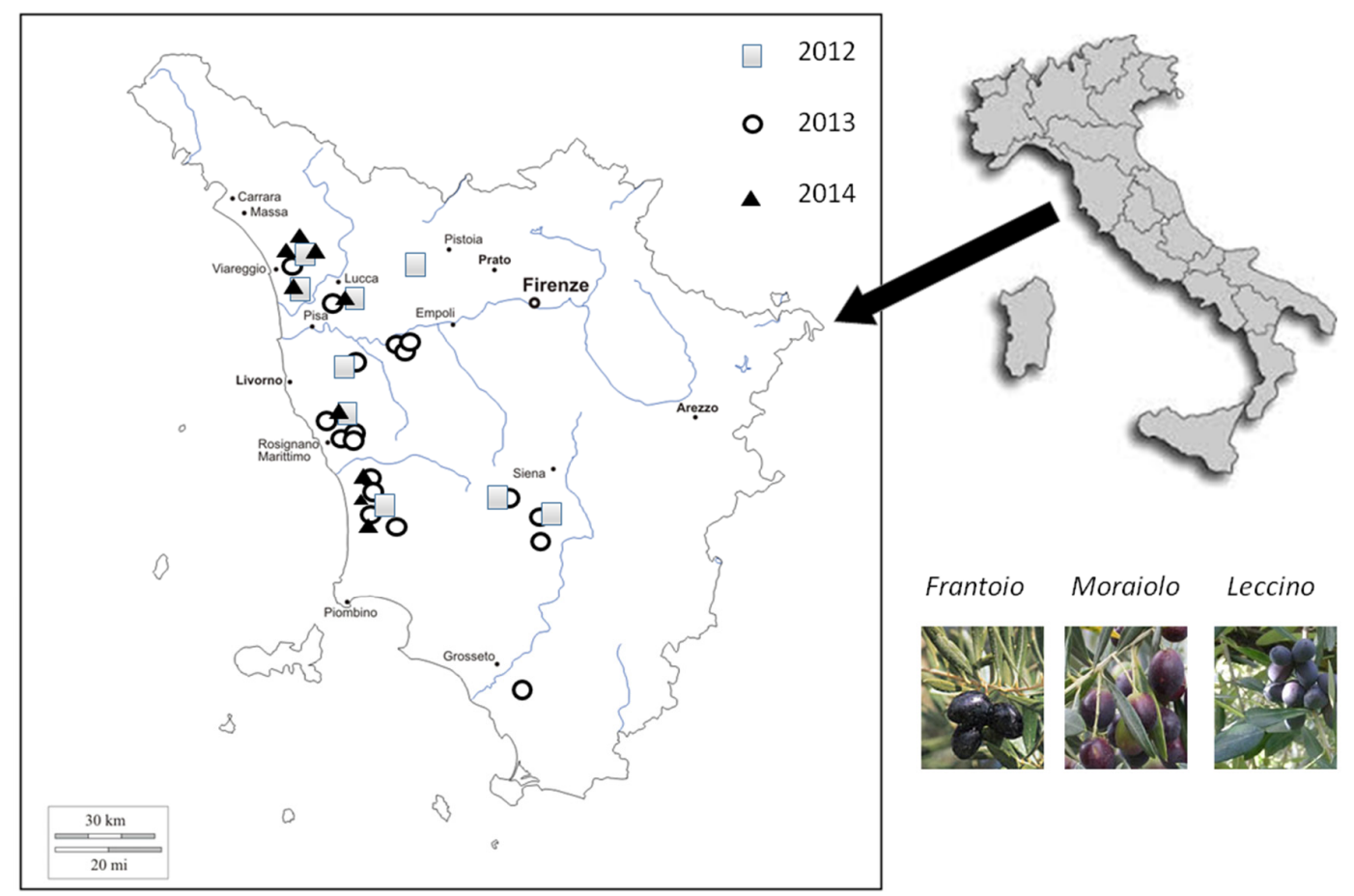

Figure 1. Extra-virgin olive oil samples of different harvesting years (2012, 2013, and 2014) produced in Tuscany (Italy) from a blend of Leccino, Moraiolo, and Frantoio cultivars. The location of olives' origin is indicated for all investigated samples.

\subsection{Method}

Near UV-visible absorbance spectra of extra virgin olive oil samples were measured with a Jasco V-550 spectrophotometer using quartz cells with $0.2 \mathrm{~cm}$ optical path length [24,25]. Before absorbance measurements, the oil samples were centrifuged for $30 \mathrm{~min}$ at $5000 \mathrm{rpm}$ in order to minimize the light absorption and scattering phenomena due to suspended particles. The absorbances of EVOO spectra were than referred to a $1 \mathrm{~cm}$ optical path and analysed by using a mathematical tool compatible with Excel, developed by Domenici et al. [24].

The mathematical treatment of the EVOO absorption spectrum allowed us to extract the concentration of the four main pigments ( $\beta$-carotene, lutein, pheophytin $A$, and pheophytin $B$ ). This mathematical approach consists of the deconvolution of the experimental spectrum in terms of four orthogonal spectra obtained from the original experimental spectra of the four pigments, as described in detail in Reference [24]. This fitting procedure gives us as an output file the concentration of the 
four pigments and other relevant parameters such as the ratio between the total amount of carotenoids and chlorophyll derivatives, the percentage of lutein with respect to the carotenoid fraction, and so on. As an example, the experimental spectrum of an EVOO sample analysed in this work is reported in Figure 2 (red curve) together with the fitted spectrum (black curve). The residuals can also be visualized as a dotted curve. The goodness of the mathematical treatment can be verified by the " $R$-square" test $\left(R^{2}\right)$, which estimates the correlation between the experimental values and the values predicted by the deconvolution procedure, and defined as:

$$
R-\text { square }=1-\frac{\sum_{i=1}^{n}\left(y_{i}-f_{i}\right)^{2}}{\sum_{i=1}^{n}\left(y_{i}-\bar{y}\right)^{2}}
$$

where $f_{i}$ is the value predicted by the fitting, $\bar{y}$ is the mean of the observed data, and $y_{i}$ is the observed data value (i.e., the absorbance value at a certain ( $i$ ) wavelength).

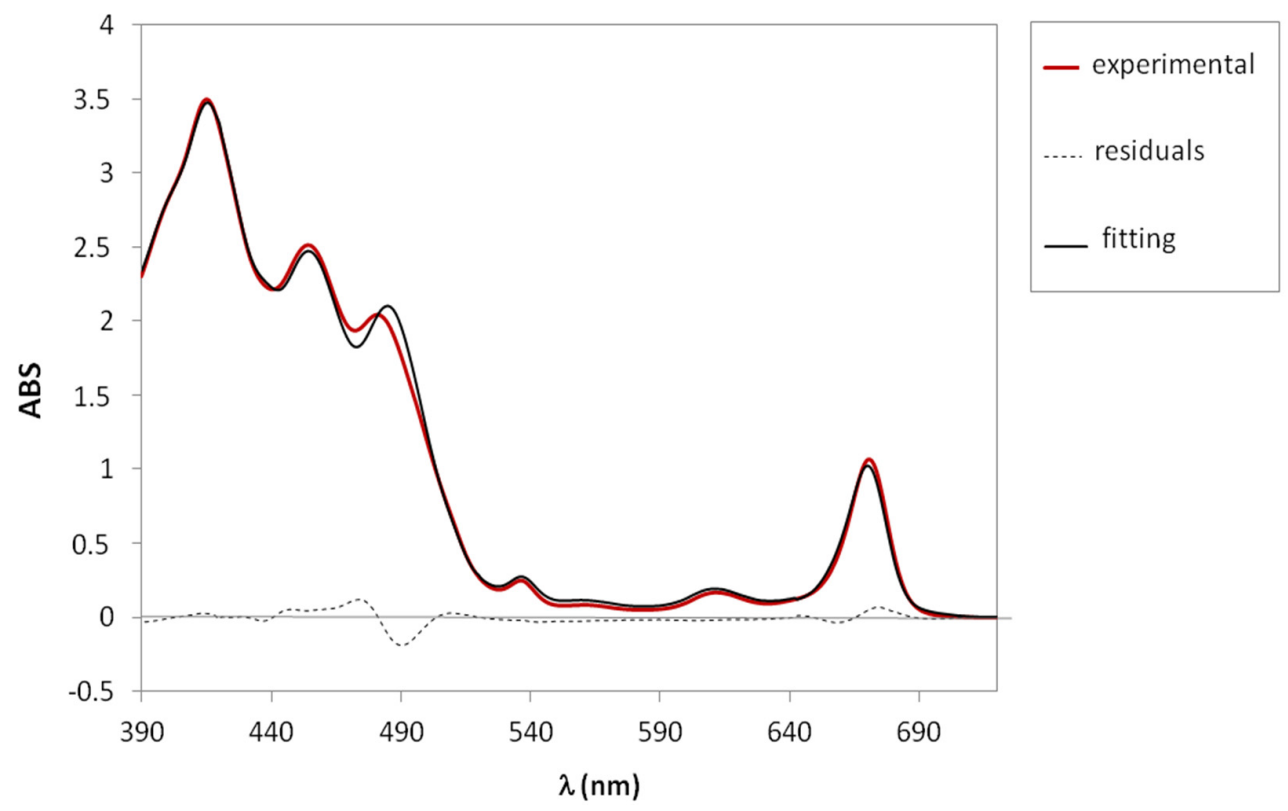

Figure 2. Example of near ultraviolet-visible (UV-vis) absorption spectrum of an extra-virgin olive oil (EVOO) sample, recorded in the range 390-720 nm. Experimental (red) and fitted (black) curves are reported with the residuals (dotted) curve.

As previously reported [24-27,41], this method was shown to be robust with high reproducibility and good sensitivity. For each EVOO sample analysed in this work, the near UV-visible spectra were measured with three replicates, and the values of concentration of the four pigments are expressed as average value \pm standard deviation (over three replicates). The coefficient $R^{2}$ of the fitting is reported for each sample in order to evaluate the goodness of the mathematical treatment.

In previous works $[14,25,26]$, we have tested the UV-vis method by applying it to a series of samples with known main pigments' concentrations, and the method was shown to be accurate. The only limitation-which is not addressed in this work-is related to the eventual presence of other minor pigments (e.g., other xanthophylls), which may contribute to the absorption in the region of the spectrum around $490 \mathrm{~nm}$, which corresponds to the highest residuals in absolute values, as shown in Figure 2.

\subsection{Statistical Analysis}

Univariate and multivariate analyses were performed by using XLSTAT software (Addinsoft, Paris, France) for EXCEL. 


\section{Results and Discussion}

\subsection{Pigments Quantification}

The main pigments - two carotenoids and two chlorophyll derivatives-were quantified by analyzing the near UV-visible spectrum of EVOO samples produced in three consecutive harvesting years from 2012 to 2014, obtained from olives produced in the western part of Central Italy, namely in Tuscany (Figure 1), from three typical cultivars: Leccino, Moraiolo, and Frantoio. The concentration (ppm) of $\beta$-carotene, lutein, pheophytin A, and pheophytin B of the EVOO samples, labeled from T1 to T37, are reported in Table 1 and in Figure 3.

Table 1. Concentration (ppm) of the four main pigments in EVOO samples, labeled from T1 to T37, from Leccino, Moraiolo, and Frantoio cultivars produced in different years in Tuscany. Data are obtained from the analysis of the near UV-vis absorption spectra. The concentration of pigments is expressed as average value \pm standard deviation (three replicates each). The coefficient $R^{2}$ of the fitting is reported for each sample.

\begin{tabular}{|c|c|c|c|c|c|}
\hline EVOO Label & $\begin{array}{c}\beta \text {-Carotene } \\
(\mathrm{ppm})\end{array}$ & $\begin{array}{l}\text { Lutein } \\
\text { (ppm) }\end{array}$ & $\begin{array}{c}\text { Pheophytin A } \\
\text { (ppm) }\end{array}$ & $\begin{array}{l}\text { Pheophytin B } \\
\text { (ppm) }\end{array}$ & $R^{2}$ \\
\hline \multicolumn{6}{|c|}{ From 2012 Harvesting } \\
\hline T1 & $2.05 \pm 0.19$ & $3.46 \pm 0.15$ & $3.52 \pm 0.11$ & $0.87 \pm 0.03$ & 0.994 \\
\hline T2 & $1.99 \pm 0.20$ & $3.32 \pm 0.31$ & $4.03 \pm 0.13$ & $0.94 \pm 0.03$ & 0.997 \\
\hline T3 & $2.44 \pm 0.18$ & $4.82 \pm 0.25$ & $4.62 \pm 0.16$ & $1.00 \pm 0.05$ & 0.998 \\
\hline $\mathrm{T} 4$ & $2.05 \pm 0.15$ & $5.24 \pm 0.61$ & $12.67 \pm 0.13$ & $1.23 \pm 0.04$ & 0.999 \\
\hline T5 & $2.28 \pm 0.11$ & $8.47 \pm 0.10$ & $15.08 \pm 0.17$ & $1.73 \pm 0.02$ & 0.998 \\
\hline T6 & $0.83 \pm 0.18$ & $3.64 \pm 0.82$ & $4.63 \pm 0.15$ & $0.64 \pm 0.05$ & 0.998 \\
\hline T7 & $0.73 \pm 0.15$ & $4.67 \pm 0.22$ & $2.14 \pm 0.22$ & $0.62 \pm 0.02$ & 0.998 \\
\hline $\mathrm{T} 8$ & $1.08 \pm 0.12$ & $3.46 \pm 0.11$ & $6.11 \pm 0.13$ & $0.78 \pm 0.05$ & 0.998 \\
\hline T9 & $1.83 \pm 0.11$ & $4.63 \pm 0.14$ & $8.33 \pm 0.18$ & $0.98 \pm 0.06$ & 0.998 \\
\hline \multicolumn{6}{|c|}{ From 2013 Harvesting } \\
\hline T10 & $1.17 \pm 0.12$ & $3.42 \pm 0.12$ & $5.53 \pm 0.12$ & $1.36 \pm 0.03$ & 0.997 \\
\hline T11 & $1.29 \pm 0.11$ & $4.37 \pm 0.08$ & $7.64 \pm 0.22$ & $0.74 \pm 0.05$ & 0.998 \\
\hline T12 & $1.04 \pm 0.18$ & $3.86 \pm 0.13$ & $5.78 \pm 0.16$ & $0.81 \pm 0.06$ & 0.998 \\
\hline T13 & $1.73 \pm 0.14$ & $3.17 \pm 0.21$ & $7.83 \pm 0.23$ & $1.20 \pm 0.10$ & 0.998 \\
\hline T14 & $1.67 \pm 0.11$ & $3.83 \pm 0.13$ & $8.68 \pm 0.29$ & $0.66 \pm 0.08$ & 0.999 \\
\hline T15 & $0.52 \pm 0.21$ & $3.88 \pm 0.41$ & $2.41 \pm 0.10$ & $0.42 \pm 0.05$ & 0.998 \\
\hline T16 & $0.73 \pm 0.15$ & $2.52 \pm 0.03$ & $3.74 \pm 0.12$ & $0.50 \pm 0.06$ & 0.998 \\
\hline T17 & $1.96 \pm 0.18$ & $3.81 \pm 0.22$ & $7.93 \pm 0.11$ & $1.06 \pm 0.03$ & 0.998 \\
\hline $\mathrm{T} 18$ & $1.10 \pm 0.18$ & $4.47 \pm 0.12$ & $5.43 \pm 0.11$ & $0.55 \pm 0.08$ & 0.998 \\
\hline T19 & $1.83 \pm 0.13$ & $5.32 \pm 0.21$ & $8.12 \pm 0.10$ & $0.91 \pm 0.03$ & 0.998 \\
\hline $\mathrm{T} 20$ & $1.26 \pm 0.10$ & $5.03 \pm 0.31$ & $8.05 \pm 0.15$ & $0.66 \pm 0.15$ & 0.998 \\
\hline $\mathrm{T} 21$ & $2.23 \pm 0.09$ & $4.89 \pm 0.43$ & $14.41 \pm 0.18$ & $1.89 \pm 0.06$ & 0.998 \\
\hline $\mathrm{T} 22$ & $2.18 \pm 0.12$ & $5.93 \pm 0.46$ & $11.68 \pm 0.21$ & $1.28 \pm 0.03$ & 0.997 \\
\hline $\mathrm{T} 23$ & $2.00 \pm 0.18$ & $5.04 \pm 0.10$ & $13.34 \pm 0.11$ & $0.86 \pm 0.02$ & 0.998 \\
\hline $\mathrm{T} 24$ & $1.76 \pm 0.14$ & $3.92 \pm 0.12$ & $6.57 \pm 0.15$ & $0.76 \pm 0.01$ & 0.998 \\
\hline T25 & $1.92 \pm 0.14$ & $5.05 \pm 0.12$ & $9.73 \pm 0.10$ & $0.91 \pm 0.03$ & 0.997 \\
\hline $\mathrm{T} 26$ & $1.51 \pm 0.15$ & $2.70 \pm 0.14$ & $5.12 \pm 0.18$ & $0.69 \pm 0.04$ & 0.999 \\
\hline $\mathrm{T} 27$ & $1.00 \pm 0.21$ & $2.12 \pm 0.15$ & $3.10 \pm 0.16$ & $0.43 \pm 0.06$ & 0.998 \\
\hline \multicolumn{6}{|c|}{ From 2014 Harvesting } \\
\hline $\mathrm{T} 28$ & $3.12 \pm 0.14$ & $1.79 \pm 0.18$ & $9.32 \pm 0.13$ & $1.02 \pm 0.02$ & 0.993 \\
\hline T29 & $2.95 \pm 0.19$ & $1.90 \pm 0.22$ & $5.64 \pm 0.16$ & $0.77 \pm 0.05$ & 0.991 \\
\hline T30 & $3.49 \pm 0.18$ & $3.03 \pm 0.12$ & $11.78 \pm 0.11$ & $1.44 \pm 0.03$ & 0.988 \\
\hline T31 & $2.88 \pm 0.22$ & $2.18 \pm 0.25$ & $7.65 \pm 0.10$ & $1.09 \pm 0.04$ & 0.996 \\
\hline T32 & $2.82 \pm 0.12$ & $2.73 \pm 0.10$ & $7.83 \pm 0.09$ & $1.13 \pm 0.08$ & 0.983 \\
\hline T33 & $4.23 \pm 0.26$ & $4.82 \pm 0.21$ & $14.22 \pm 0.11$ & $1.79 \pm 0.03$ & 0.989 \\
\hline $\mathrm{T} 34$ & $3.45 \pm 0.28$ & $4.03 \pm 0.26$ & $11.77 \pm 0.15$ & $1.49 \pm 0.00$ & 0.997 \\
\hline T35 & $2.87 \pm 0.26$ & $3.01 \pm 0.18$ & $9.94 \pm 0.18$ & $1.20 \pm 0.02$ & 0.991 \\
\hline T36 & $3.37 \pm 0.09$ & $3.20 \pm 0.21$ & $10.74 \pm 0.21$ & $0.92 \pm 0.02$ & 0.998 \\
\hline T37 & $3.90 \pm 0.14$ & $3.85 \pm 0.17$ & $9.31 \pm 0.10$ & $1.29 \pm 0.05$ & 0.998 \\
\hline
\end{tabular}




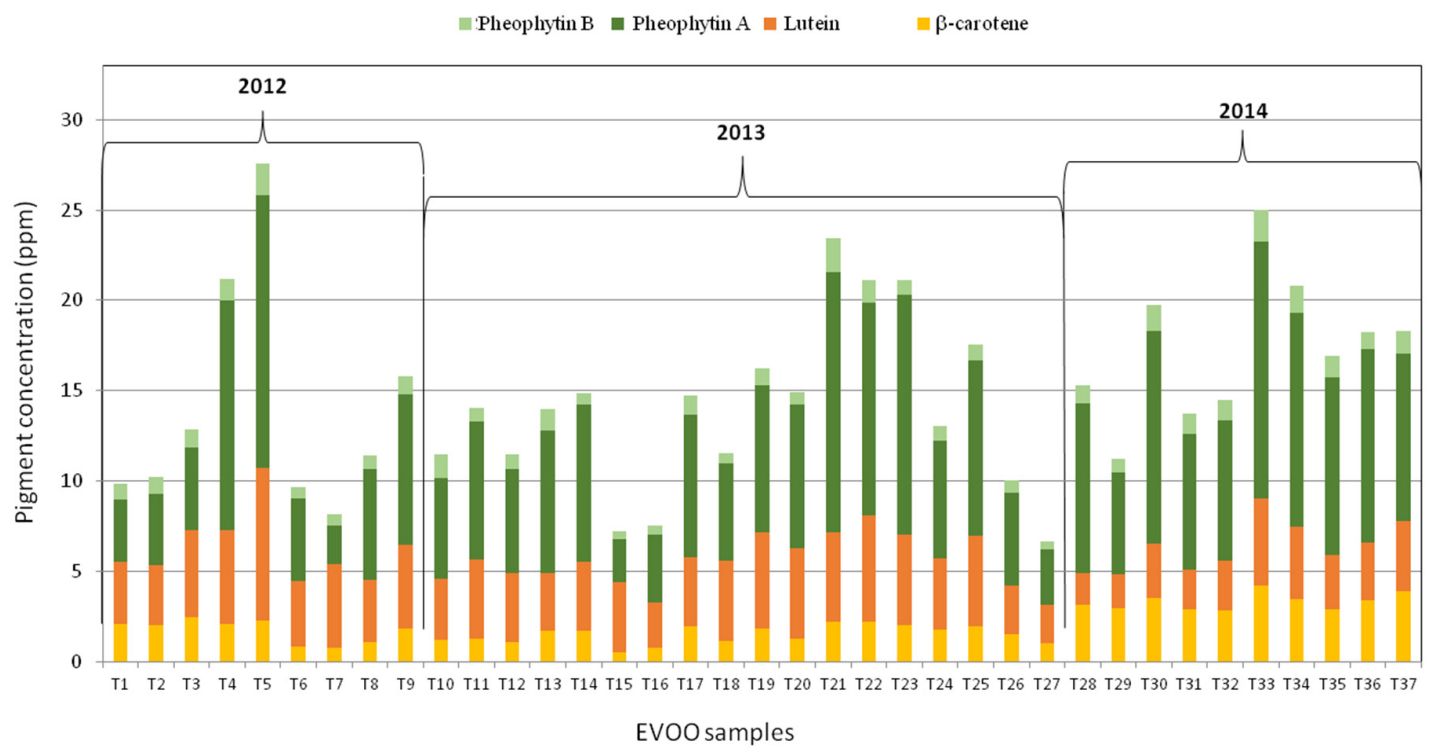

Figure 3. Profile of the four main pigments ( $\beta$-carotene, lutein, pheophytin A, and pheophytin B) determined by the mathematical analysis of the near UV-vis absorption spectra of the EVOO samples investigated in this work. Samples are labelled from T1 to T37, as shown in Table 1. Three groups of samples can be visualized depending on the year of olive harvesting $(2012,2013$, and 2014).

The concentrations of the four pigments were obtained with relatively high accuracy $[14,25,26]$ in comparison with conventional chromatographic methods [3-6]. The goodness of the fitting procedure needed for the extraction of pigment contents from the analysis of the absorption spectrum was confirmed by the values of the determination coefficient, $R^{2}$, which reached the highest value of 0.999 for three samples (T4, T14, and T26) and the lowest value of 0.983 for one sample (T32).

In Figure 3, the variation of pigment content among the EVOO samples can be well visualized. As a general remark, the highest content of pigments was obtained for an EVOO sample produced in 2012 (27.58 ppm), and the lowest value of total pigments was $6.65 \mathrm{ppm}$, obtained in an EVOO sample produced in 2013. The average value of the total amount of pigments observed in this set of EVOO samples was about $15 \mathrm{ppm}$, but-as seen from the pigment profile shown in Figure 3-the differences related to the total amount of pigments among the three years are quite significant, without showing specific trends within each year.

However, there are other parameters related to the pigments' content which vary significantly among the three years of olive harvesting. An important parameter associated with pigments is the ratio between total amount of chlorophyll derivatives and the total amount of carotenoids-namely, the ratio $\mathrm{P} / \mathrm{C}$. The average value of $\mathrm{P} / \mathrm{C}$ in the three years was: $1.18 \pm 0.46$ (2012), $1.46 \pm 0.37$ (2013), and $1.73 \pm 0.26$ (2014). This ratio is considered a quality parameter for EVOO samples [4,5]. For instance, according to Roca and Minguez-Mosquera [42], this ratio should be around 1.14, shifting in the range 0.53-1.40 depending on the quality of EVOOs. Other studies indicate that this ratio can assume values in a much larger range, because it may vary sensibly depending on the cultivar, geographic olive trees cultivation, and climate conditions $[9,12-14,26]$, as confirmed by the case presented in this work.

Another important parameter is the percentage of lutein over the sum of carotenoids $(\%$ of lutein) [4,5]. In this respect, the differences between the first two years (2012 and 2013) and the year 2014 were very significant. The average value of "\% of lutein" was $73 \% \pm 8 \%$ and $73 \% \pm 6 \%$ in EVOOs produced in 2012 and in 2013, respectively. In the case of EVOOs produced in 2014, this percentage was much lower $(47 \% \pm 6 \%)$. As shown in Figure 4, the anomaly of the EVOO samples produced in 2014 is related to the high content of $\beta$-carotene with respect to lutein. 


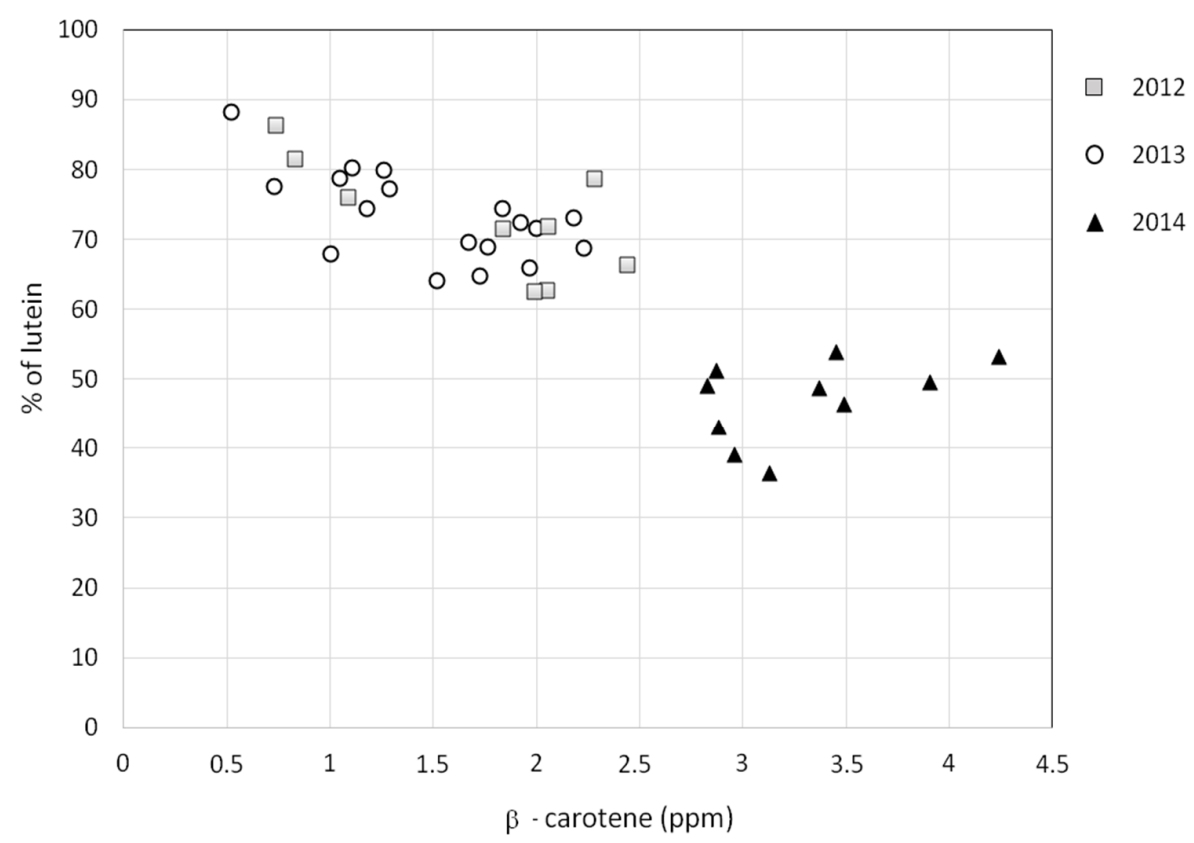

Figure 4. Plot of the parameter "\% of lutein" (over the carotenoid fraction) versus the concentration (ppm) of $\beta$-carotene for the EVOO samples investigated in this work. Samples are labeled according to the harvest year.

\subsection{Multivariate Data Analysis}

Data obtained by the analysis of near UV-visible absorption spectra were further analyzed by means of principal component analysis (PCA). In this analysis, we have identified nine variables: the concentrations of the four pigments, the total amount of pigments, the carotenoid and chlorophyll derivative fractions, the $\mathrm{P} / \mathrm{C}$ ratio, and the $\%$ of lutein. The PCA results reported in Figure 5 indicate that the parameters analyzed have a distinct response pattern in EVOOs produced in 2012 and 2013 compared to EVOOs produced in 2014, supporting previous considerations. In particular, PCA analysis produced two significant components that, together, explain $88.3 \%$ of the total variance. The first component (PC 1, explaining $64.7 \%$ of the total variance) includes seven variables ( $\beta$-carotene, pheophytins $\mathrm{A}$ and $\mathrm{B}$, sum of pigments, total carotenoids, total chlorophyll derivatives, and the $\mathrm{P} / \mathrm{C}$ ratio). Lutein and the $\%$ of lutein are associated with the second component PC 2 (23.6\% of the variance).

A scatter plot of the scores of different treated samples in the score space PC 1/PC 2 is shown in Figure 5A. EVOO samples produced in 2014 (black triangles) are clearly distinguished from the EVOOs produced in 2012 (grey squares) and 2013 (empty circles). In particular, almost all 2014 EVOO samples are in the fourth quarter (positive PC 1 and negative PC 2), while $77 \%$ of EVOO samples produced in 2012 and 2013 have positive PC 2 (first and second quarters).

The PCA loading plot is reported in Figure 5B, showing the distribution of variables. Some of them are highly correlated, such as the sum of pigments, the sum of chlorophyll derivatives, and the single concentrations of pheophytins A and B. Their combined use in the multivariate analysis does not modify the results. All other parameters are not significantly correlated. 

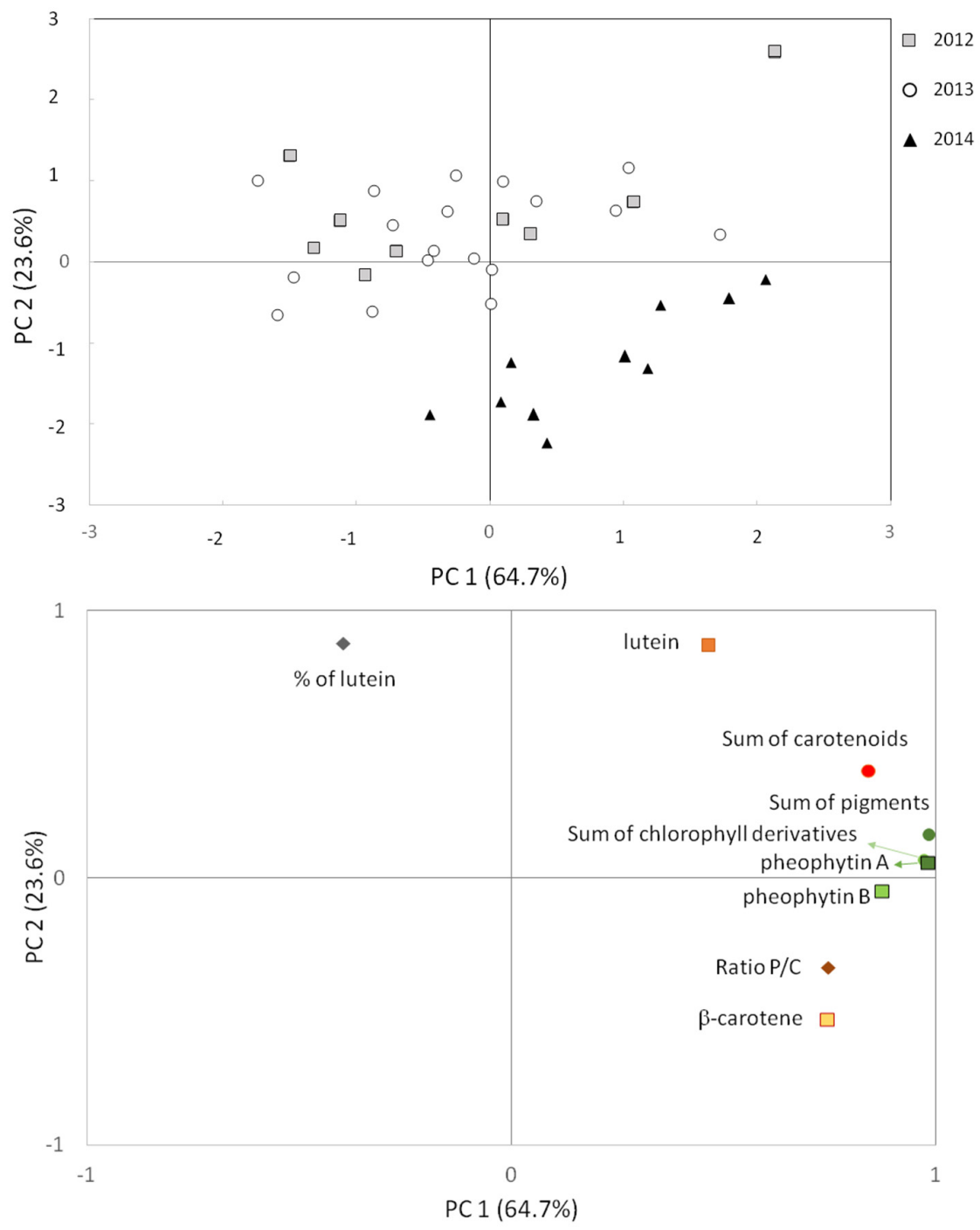

Figure 5. Results of the multivariate analysis. (A) Score plot of the principal component analysis (PCA) modelling, showing the EVOO samples harvested in $2012(\boldsymbol{\square}), 2013(\bigcirc)$, and 2014 (A); (B) Loading plot of the PCA modelling, showing the variables used for the analysis. P/C: ratio between total amount of chlorophyll derivatives and the total amount of carotenoids.

The PCA results confirm previous observations about the anomalous values of $\beta$-carotene and $\%$ of lutein of samples produced in 2014 with respect to previous years. These anomalies can be associated with the particular conditions of the 2014 crop season. As reported in Reference [37], the climatic anomalies observed during the period from June to October $2014[38,39]$ strongly affected Tuscany, and almost all olive trees were damaged by the attack of Bactrocera oleae. The olive oils produced in that period in Tuscany were characterized by lower values of phenolic/tocopherol compounds and higher free acidity than previous harvesting years. The fly attack brought to an alteration of the metabolic processes typical of the olives [37] and a different exposure to oxygen. These reasons may be at the origin of an alteration of the pigment profile observed in the present study. Other reasons could be related to the different harvesting period, which was slightly early in 2014 with respect to 2012 and 2013. The anticipation of harvesting on the other hand was related to the particular weather conditions. Other factors usually influencing olive oil pigment profiles, such as cultivar, geographic origin, olive oil treatment and production processes seem not be relevant in this case, since all these factors were the same in the three different harvesting years. 


\section{Conclusions}

Pigment content of extra virgin olive oils produced from a blend of three cultivars typical of Tuscany-namely Leccino, Frantoio, and Moraiolo—in three different years (2012, 2013, and 2014) was determined by analyzing the absorption spectrum in the near UV-visible region of each sample. The method is fast, non-destructive, and relatively cheap, and allowed us to obtain the concentration of the four main pigments present in EVOOs: $\beta$-carotene, lutein, pheophytin A, and pheophytin B. Relevant parameters, such as the ratio between the chlorophyll derivatives and the carotenoids $(\mathrm{P} / \mathrm{C})$ and the percentage of lutein (\% lutein) were calculated. The results show that EVOOs produced in 2014 had a high content of $\beta$-carotene with respect to lutein, showing an anomalous value of $\%$ of lutein. The anomalous climate conditions affecting Tuscany between June and October 2014-which in turn were at the origin of one of the strongest fly attack of the last decade-are among the most probable reasons of the anomalous pigment profile in EVOO produced in 2014, with respect to previous years. In fact, all other factors influencing the pigment profiles in olive oil were the same in the three harvesting years. The anomalous climate conditions and the consequent fly attack could have affected the metabolism of olives and olive oils, resulting in a different pigment profile. This hypothesis is in agreement with other studies showing that olive oils produced in Tuscany in 2014 had anomalous content in phenolic/tocopherol compounds, free acidity, and other chemical properties. Multivariate analysis demonstrated that EVOO samples produced in Tuscany from a blend of three typical cultivars, namely Leccino, Moraiolo, and Frantoio, in 2014 can indeed be differentiated from previous harvesting years (i.e., 2012 and 2013) by their pigment composition and most relevant parameters.

Acknowledgments: Authors thank Andrea Serani and Mario Cifelli for helpful discussions. C.L. thanks SALOV Spa company for hosting her during the master thesis internship.

Author Contributions: V.D. conceived and designed the experiments; C.L. performed the experiments; V.D. and C.L. analyzed the data and wrote the paper.

Conflicts of Interest: The authors declare no conflict of interest.

\section{References}

1. Boskou, D. Olive fruits, table olives, and olive oil bioactive constituents. In Olive and Olive Oil Bioactive Constituents, 1st ed.; Boskou, D., Ed.; AOCS Press: Urbana, IL, USA, 2015; pp. 1-30.

2. Covas, M.-I.; Fito, M.; de la Torre, R. Minor Bioactive Olive Oil Components and Health: Key Data for Their Role in Providing Health Benefits in Humans. In Olive and Olive Oil Bioactive Constituents, 1st ed.; Boskou, D., Ed.; AOCS Press: Urbana, IL, USA, 2015; pp. 31-52.

3. Mínguez-Mosquera, M.I.; Gandul-Rojas, B.; Garrido-Fernández, J.; Gallardo-Guerrero, L. Pigments Present in Virgin Olive Oil. J. Am. Oil Chem. Soc. 1990, 67, 192-196. [CrossRef]

4. Gandul-Rojas, B.; Roca, M.; Gallardo-Guerrero, L. Chlorophylls and carotenoids in food products from olive tree. In Products from Olive Tree, 1st ed.; Boskou, D., Clodoveo, M.L., Eds.; InTech: Rijeka, Croatia, 2016; Chapter 5; pp. 67-98.

5. Lazzerini, C.; Cifelli, M.; Domenici, V. Extra virgin olive oil pigments: Authenticity and quality. In Products from Olive Tree, 1st ed.; Boskou, D., Clodoveo, M.L., Eds.; InTech: Rijeka, Croatia, 2016; Chapter 6; pp. 95-114.

6. Mínguez-Mosquera, M.I.; Rejavo-Navarro, L.; Gandul-Rojas, B.; Sanchez-Gomez, A.H.; Garrido-Fernández, J. Color-Pigment Correlation in Virgin Olive Oil. J. Am. Oil Chem. Soc. 1991, 68, 332-336.

7. Hammond, B.R. Dietary Carotenoids and the Nervous System. Foods 2015, 4, 698-701. [CrossRef] [PubMed]

8. Erdman, J.W.; Smith, J.W.; Kuchan, M.J.; Mohn, E.S.; Johnson, E.J.; Rubakhin, S.S.; Wang, L.; Sweedler, J.V.; Neuringer, M. Lutein and Brain Function. Foods 2015, 4, 547-564. [CrossRef] [PubMed]

9. Aparicio-Ruiz, R.; Gandul-Rojas, B.; Roca, M. Pigment Profile in Non-Spanish Olive Varieties (Olea europaea L. Var. Coratina, Frantoio, and Koroneiki). J. Agric. Food Chem. 2009, 57, 10831-10836. [CrossRef] [PubMed]

10. Giuffrida, S.; Salvo, F.; Salvo, A.; La Pera, D.; Dugo, G. Pigments composition in monovarietal olive oils from various Sicilian olive varieties. Food Chem. 2007, 101, 833-837. [CrossRef]

11. Giuffrida, D.; Salvo, F.; Salvo, A.; Cossignani, L.; Dugo, G. Pigments profile in monovarietal virgin olive oils from various Italian olive varieties. Food Chem. 2011, 124, 1119-1123. [CrossRef] 
12. Psomiadou, E.; Tsimidou, M. Pigments in Greek virgin olive oils: Occurrence and levels. J. Sci. Food Agric. 2001, 81, 640-647.

13. Criado, M.N.; Motilva, M.J.; Goni, M.; Romero, M.P. Comparative study of the effect of the maturation process of the olive fruit on the chlorophyll and carotenoid fractions of drupes and virgin oils from Arbequina and Farga cultivars. Food Chem. 2007, 100, 748-755. [CrossRef]

14. Lazzerini, C.; Cifelli, M.; Domenici, V. Pigments' content in Extra Virgin Olive Oils from different Mediterranean Countries produced in 2014. Food Sci. Technol. 2017. under review.

15. Dag, A.; Kerem, Z.; Yogev, N.; Zipori, I.; Lavee, C.; Ben-Davida, E. Influence of time of harvest and maturity index on olive oil yield and quality. Sci. Hortic. 2011, 170, 358-366. [CrossRef]

16. Criado, M.N.; Romero, M.P.; Casanovas, M.; Motilva, M.J. Pigment profile and colour of monovarietal virgin olive oils from Arbequina cultivar obtained during two consecutive crop seasons. Food Chem. 2008, 110, 873-880. [CrossRef] [PubMed]

17. Tura, D.; Gigliotti, C.; Pedò, S.; Failla, O.; Bassi, D.; Serraiocco, A. Influence of cultivar and site of cultivation on levels of lipophilic and hydrophilic antioxidants in virgin olive oils (Olea Europea L.) and correlations with oxidative stability. Sci. Hort. 2007, 112, 108-119. [CrossRef]

18. Criado, M.N.; Romero, M.P.; Motilva, M.J. Effect of the technological and agronomical factors on pigment transfer during olive oil extraction. J. Agric. Food Chem. 2007, 55, 5681-5688. [CrossRef] [PubMed]

19. Gandul-Rojas, B.; Cepero, M.R.L.; Minguez-Mosquera, M.I. Use of chlorophyll and carotenoid pigment composition to determine authenticity of virgin olive oil. J. Am. Oil Chem. Soc. 2000, 77, 853-858. [CrossRef]

20. Jolayemi, O.S.; Tokatli, F.; Ozen, B. Effects of malaxation temperature and harvest time on the chemical characteristics of olive oils. Food Chem. 2016, 211, 776-783. [CrossRef] [PubMed]

21. Ranalli, A.; Malfatti, A.; Lucera, L.; Contento, S.; Sotiriou, E. Effect of processing techniques on the natural colourings and the other functional constituents in virgin olive oil. Food Res. Int. 2005, 38, 873-878. [CrossRef]

22. Cayuela, J.A.; Yousfi, K.; Martinez, M.C.; Garcia, J.M. Rapid Determination of Olive Oil Chlorophylls and carotenoids by Using Visible Spectroscopy. J. Am. Oil Chem. Soc. 2014, 91, 1677-1684. [CrossRef]

23. Minguez-Mosquera, M.I.; Gandul-Rojas, B.; Gallardo-Guerrero, M.L. Rapid Method of Quantification of Chlorophylls and Carotenoids in Virgin Olive Oil by High-Performance Liquid Chromatography. J. Agric. Food Chem. 1992, 40, 60-63. [CrossRef]

24. Domenici, V.; Ancora, D.; Cifelli, M.; Serani, A.; Veracini, C.A.; Zandomeneghi, M. Extraction of Pigment Information from Near-UV Vis Absorption Spectra of Extra Virgin Olive Oils. J. Agric. Food Chem. 2014, 62, 9317-9325. [CrossRef] [PubMed]

25. Ancora, D. UV-Vis and 1H-NMR Spectroscopic Methods Applied to the Study of Extra-Virgin Olive Oil Produced in Tuscany and Apulia. Master's Thesis, University of Pisa, Pisa, Italy, 15 June 2014.

26. Lazzerini, C. Application of a New Spectrophotometric Method to Quantify Pigments in Extra-Virgin Olive Oils and Comparison with Chromatographic Techniques. Master's Thesis, University of Pisa, Pisa, Italy, 16 July 2016.

27. Lazzerini, C.; Buti, F.; Cifelli, M.; Zandomeneghi, M.; Domenici, V. Olio di oliva extravergine Toscano: Uno studio sul contenuto dei pigmenti e prospettive per un nuovo indice di qualità. In Codice Armonico. Sesto Congress di Scienze Naturali Ambiente Toscano, 1st ed.; Associazione Amici della Natura Rosignano, Ed.; Edizioni ETS: Pisa, Italy, 2016; pp. 155-165.

28. Piscolla, G.; Zoppi, L. L'Olivo in Toscana (The Olive Tree in Tuscany); Agenzia di Promozione Economica della Toscana: Firenze, Italy, 2001.

29. Olio Extra Vergine di Toscana. Available online: http://www.olioextraverginetoscana.it/cultivar-oliotoscana.php (accessed on 28 February 2017).

30. Cecchi, L.; Migliorini, M.; Cherubini, C.; Innocenti, M.; Mulinacci, N. Whole Lyophilized Olives as Sources of Unexpectedly High Amounts of Secoiridoids: The Case of Three Tuscan Cultivars. J. Agric. Food Chem. 2015, 63, 1175-1185. [CrossRef] [PubMed]

31. Cecchi, L.; Migliorini, M.; Cherubini, C.; Giusti, M.; Zanoni, B.; Innocenti, M.; Mulinacci, N. Phenolic profiles, oil amount and sugar content during olive ripening of three typical Tuscan cultivars to detect the best harvesting time for oil production. Food Res. Intern. 2013, 54, 1876-1884. [CrossRef]

32. Rotondi, A.; Fabbri, A.; Ganino, T. Sensory and chemical properties of extra virgin olive oils produced in two different Italian regions: Tuscany and Emilia-Romagna. J. Food Agric. Environ. 2008, 6, 71-77. 
33. Cimato, A.; Franchini, E.; Lapucci, C.; Attilio, C.; Sani, G.; Costantini, E.A.C.; Pellegrini, S.; Barbetti, R. Qualità di oli monovarietali da olive "Frantoio" e relazione con suoli della provincia di Siena. In Proceedings of the National Conference on Qualità del Suolo, Impatto Antropico e Qualita' dei Prodotti Agricoli, Siena, Italy, 9-12 June 2003; pp. 428-433. (In Italian)

34. Bendini, A.; Cerretani, L.; Salvador, M.D.; Fregapane, G.; Lercker, G. Stability of the sensory quality of virgin olive oil during storage: An overview. Ital. J. Food Sci. 2009, 21, 389-406.

35. Bucelli, P.; Costantini, E.A.C.; Barbetti, R.; Franchini, E. Soil Water Availability in Rainfed Cultivation Affects More than Cultivar Some Nutraceutical Components and the Sensory Profile of Virgin Olive Oil. J. Agric. Food Chem. 2011, 59, 8304-8313. [CrossRef] [PubMed]

36. Mari, E.; Guerrini, S.; Granchi, L. Enumeration and rapid identification of yeasts during extraction processes of extra virgin olive oil in Tuscany. World J. Microbiol. Biotechnol. 2016, 32. [CrossRef] [PubMed]

37. Cecchi, L.; Migliorini, M.; Cherubini, C.; Trapani, S.; Zanoni, B. The case of the 2014 crop season in Tuscany: A survey of the effect of the olive fruit fly attack. Ital. J. Food Sci. 2016, 28, 352-361.

38. Consorzio Lamma. Available online: http:/ / www.lamma.rete.toscana.it (accessed on 28 February 2017).

39. Consorzio Lamma News "Clima 2014 in Toscana: Anomalie, Record e Curiosità". Available online: http:/ / www.lamma.rete.toscana.it/news / clima-2014-toscana-anomalie-record-e-curiosit\%C3\%A0 (accessed on 28 February 2017).

40. Loudiyi, W.D.; Chmitah, M.; Loussert, R.; Mahhou, A.; Boulouha, B. Morphologic and physiologic characters of olive clones from Picholine Marroqui variety. Olivae 1984, 3, 26-31.

41. Domenici, V.; Lazzerini, C.; Cifelli, M. Pigments' Content of Extra Virgin Olive Oils from Different European Countries Produced in 2014. In Proceedings of the 106th AOCS Annual Meeting on Poster Communication, Orlando, FL, USA, 3-6 May 2015.

42. Roca, M.; Minguez-Mosquera, M.I. Change in the natural ratio between chlorophylls and carotenoids in olive fruit during processing for virgin olive oil. J. Amer. Oil Chem. Soc. 2001, 78, 133-138. [CrossRef]

(C) 2017 by the authors. Licensee MDPI, Basel, Switzerland. This article is an open access article distributed under the terms and conditions of the Creative Commons Attribution (CC BY) license (http:/ / creativecommons.org/licenses/by/4.0/). 